\title{
Padrões de prática no ensino de ciências pela utilização de um instrumento designado radiografia da prática
}

\author{
Patterns of science teaching practice with the use \\ of an instrument designated "X ray of practice"
}

José Manuel Carmo1 . https://orcid.org/0000-0003-0927-975X

\begin{abstract}
Resumo: $\mathrm{O}$ artigo descreve uma proposta de instrumento para a recolha de uma descrição operacional da prática de professores que permita aceder aos acontecimentos pedagógicos essenciais que estruturam as suas práticas, ao osso físico da sua teoria prática que se designa radiografia da prática. A metodologia anteriormente proposta para identificar as sequências pedagógicas dos professores é, neste trabalho, utilizada como matriz interpretativa pelo investigador das descrições da prática dos professores, experimentando a sua utilidade e contribuindo para a validação dos pressupostos na sua construção. No artigo descreve-se o procedimento metodológico na sua aplicação a um conjunto de professores, o processo de inferência pelo investigador e exemplos dos padrões de prática encontrados no grupo estudado: um padrão mais radicalmente transmissivo, um padrão transmissivo baseado numa atividade prática e um padrão com marcas construtivistas.
\end{abstract}

Palavras-chave: Sequências pedagógicas. Método construtivista. Ensino de ciências. Prática de ensino. Metodologia do ensino.

\begin{abstract}
The article describes a proposal for an instrument for collecting a description of the operational practice of teachers, allowing for access to essential educational events that structure their practices, the physical bone of their theory practice, designated X-ray of the practice. The methodology previously proposed to identify the teachers' pedagogical sequences is, in this work, used as an interpretive matrix by the investigator of the descriptions of the teachers' practice, experiencing its usefulness and contributing to the validation of the assumptions in its construction. The article describes the methodological procedure in the application with a group of teachers, the process of inference by the investigator, and examples of the practice patterns found in the studied group: a pattern radically more transmissive, a transmissive pattern based on a practical activity and a pattern with constructivist indications.
\end{abstract}

Keywords: Pedagogical sequences. Constructivist method. Science teaching. Teaching practice. Teaching methodology.

\footnotetext{
${ }^{1}$ Universidade do Algarve, Escola Superior de Educação e Comunicação, Departamento de Ciências Exatas e Naturais, Campos da Penha, Faro, Portugal. Email: jmbcarmo@gmail.com
} 


\section{Introdução}

Embora os estudos debaixo do guarda-chuva da investigação Teaching-Learning Sequence (TLS) estejam relacionados com o desenvolvimento, validação e apreciação do impacto no ensino de produtos para o ensino visando uma perspetiva construtivista (MÉHEUT; PSILLOS, 2004), no entanto, esta linha de pesquisa quando aplicada às sequências de ensino produzidas pelos professores, permite também um olhar analítico e crítico, portanto também formativo, sobre as conceções de prática dos professores que as elaboram.

Nesta linha, Rivero et al. (2017) solicitam aos professores em formação o delineamento de propostas de sequências didáticas para o ensino sobre um tópico concreto que analisam relativamente a aspetos como apresentação dos conteúdos aos alunos, utilização didática das ideias dos alunos, sequência metodológica e significado da avaliação, classificando-as em três níveis de uma perspetiva tradicional ou transmissiva a uma perspetiva que designam investigação escolar, visando conhecer em que medida a perspetiva construtivista se incorpora no conhecimento profissional dos professores. Estas propostas de sequências didáticas permanecem como referentes durante o processo de formação, permitindo acompanhar a progressão em direção a um modelo desejável.

A partir da descrição pelos professores da sequência que utilizam em sala de aula, relativamente ao ensino de um conteúdo, em que especificam como iniciam a aula, como se processa o seu desenvolvimento e como avaliam as aprendizagens, Morelatti et al. (2014), evidenciam a existência de três padrões de prática: $(\mathrm{P})$ atividades realizadas pelo professor, $(\mathrm{C})$ atividades compartilhadas por professor e aluno e (A) atividades realizadas pelos alunos. No conjunto da sua amostra, os autores referidos (MORELATTI et al., 2014) encontram no início da sequência de ensino, $18 \%$ de professores situando-se no padrão A.

As metodologias utilizadas nos referidos estudos, embora permitindo o conhecimento da teoria-prática e a recolha de muita informação sobre o pensamento pedagógico dos professores, não contribui para o desenvolvimento de um instrumento expedito para utilização em uma metodologia construtivista de formação contínua, que pretenda partir das conceções prévias dos participantes e desenrolar-se como uma reflexão teoricamente fundamentada sobre as práticas.

Procurando caracterizar a metodologia aplicada na sala de aula, de um modo expedito e sem a presença de um observador, a metodologia designada sequência pedagógica (CARMO, 2016) parte da identificação de um conjunto de aspetos, ou acontecimentos pedagógicos invariantes (Quadro 1) definidos com um elevado grau de generalidade que poderão estar presentes em qualquer estrutura metodológica. No entanto, os acontecimentos pedagógicos que os respondentes selecionam como presentes e a ordem em que consideram que surgem no início de uma sequência de ensino diferem com a orientação metodológica subjacente. Aos professores respondentes se lhes pede que selecionem os itens do Quadro 1 que consideram estar presentes e os ordenem como consideram que ocorrem no início de uma sequência de ensino de determinada unidade didática, deste modo gerando uma sequência pedagógica característica desse professor. As sequências pedagógicas produzidas pelos professores que indicam no início da sequência de ensino acontecimentos pedagógicos centrados nos alunos (itens C, D e F) caracterizariam professores revelando uma tendência mais orientada para estratégias de natureza construtivista; pelo contrário, uma sequência pedagógica iniciando-se por acontecimentos pedagógicos centrados no professor (itens A, E, G) corresponderia a um perfil tradicional transmissivo. A 
frase B (os alunos têm oportunidade de contactar com situações ou acontecimentos relativos ao assunto) tanto pode corresponder a uma oportunidade para exploração pelo aluno, a partir da qual se inicia um ciclo de construção do conhecimento, a uma contextualização necessária para que o professor explique a matéria, ou ainda, a um momento de ilustração ou de aplicação de conhecimentos anteriormente ensinados pelo professor.

$\mathrm{Na}$ investigação referida, os professores no grupo construtivista revelaram outros parâmetros consistentes com a adoção de uma perspetiva mais centrada no aluno, nomeadamente, a perceção de mais tempo de ensino ocupado com a promoção de processos de pensamento científico e a perceção pelos seus alunos do maior contributo para a aprendizagem de aspetos como a atividade experimental e o trabalho em grupo com os colegas, e o menor contributo do impacto das explicações e das demonstrações feitas pelo professor.

O objetivo deste estudo é, dentro da linha metodológica da redação de sequências de ensino, desenvolver um instrumento para a recolha de uma descrição operacional da prática desenvolvida por um professor que, embora perdendo a riqueza de outras metodologias, como os diários do professor, permita aceder aos acontecimentos pedagógicos essenciais que estruturam a prática de um professor, ao osso físico da sua teoria prática que designaremos radiografia da prática. Este procedimento metodológico deverá permitir a inferência de uma sequência pedagógica pelo investigador e o debate formativo sobre o significado teórico dos acontecimentos descritos. Um segundo objetivo é contribuir para a validação da metodologia anteriormente proposta para a identificação da sequência pedagógica de professores, experimentando a sua utilidade como matriz interpretativa das descrições da prática de professores.

Neste artigo descrevem-se os resultados da aplicação destes procedimentos a um conjunto de professores, o processo de análise e inferência pelo investigador de uma sequência pedagógica, apresentando-se exemplos dos padrões de prática encontrados no grupo estudado.

\section{Metodologia}

A metodologia descrita foi aplicada no início de curso de formação contínua de professores visando a promoção do ensino experimental no $1^{\circ}$ ciclo do Ensino Básico incluída num programa nacional fortemente promovido e abrangendo muitas centenas de professores. Este curso, em particular, estava focado no tema futuação. Os instrumentos foram aplicados aos 65 participantes de um dos núcleos deste programa na região do Algarve, Portugal, tendo-se recolhido 43 respostas.

Radiografia da prática: aos participantes é apresentada uma página com duas colunas em que é pedido que, em relação ao tópico em foco no curso de formação - flutuação - descrevam no lado esquerdo, passo a passo, as ações do professor no início do processo de ensino-aprendizagem desse tópico programático, nomeadamente, o que diz o professor, o que faz, o que manda fazer e as orientações que dá. Do lado direito da folha os participantes são convidados a descrever as ações dos alunos, nomeadamente o que fazem e dizem em paralelo com as ações do professor. Esta tarefa é solicitada no início da ação de formação, previamente a qualquer outra atividade, exceto questões exclusivamente burocráticas. 
Quadro 1 - Acontecimentos pedagógicos presentes no ensino, independentemente da orientação metodológica adotada

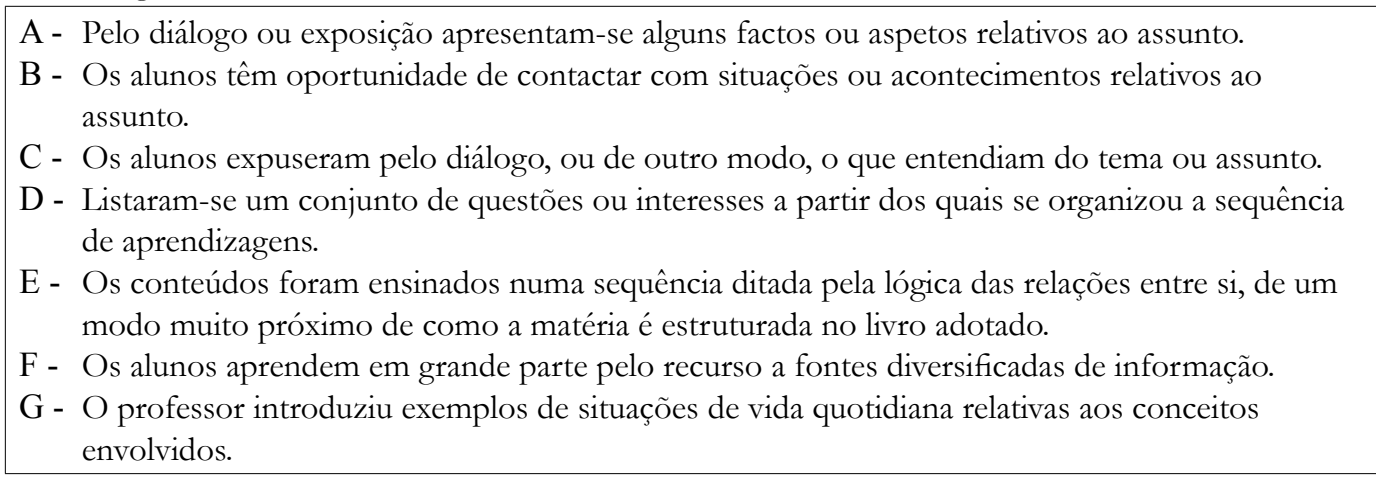

Fonte: Elaborado pelo autor (CARMO, 2016).

Sequência pedagógica: embora esta metodologia seja descrita pelo autor para ser utilizada pelos professores selecionando os itens numa ordem que melhor traduz a sequência de ensino que utilizam, neste estudo o Quadro 1 foi utilizado pelo investigador para interpretar as ações descritas pelo professor no Relatório da Prática (CARMO, 2016). As asserções constantes do Relatório da Prática com que o professor descreve a sua ação e a correspondente ação dos alunos são interpretadas pelo investigador e classificadas em cada uma das sete categorias de acontecimentos pedagógicos (itens $\mathrm{A}$ a $\mathrm{G}$ do quadro 1). Deste modo, o investigador gera uma sequência pedagógica para cada um dos participantes no estudo.

\section{Resultados}

Os resultados da análise dos 43 Relatórios da Prática recolhidos permitiram a identificação de três padrões de prática na amostra analisada. Os anexos 1, 2 e 3 reproduzem, para cada um destes padrões, dois exemplos da transcrição do texto dos relatórios da prática produzidos pelos professores sobre o modo como organizam o seu ensino relativamente ao tópico futuação. Segue-se a interpretação do investigador relativamente às asserções constantes dos relatórios da prática de cada um dos respondentes (entre aspas) e sua classificação em uma das categorias de acontecimentos pedagógicos do quadro 1 (em itálico), com a correspondente inferência de uma sequência pedagógica e respetiva discussão.

\section{Padrão 1 - perfil mais radicalmente transmissivo (Anexo A)}

\section{Sujeito $\mathbf{n}^{\mathbf{0}} 10$}

Primeiro momento: o professor "questionando o conceito de flutuação" e os alunos "respondendo dando exemplos e as suas opiniões"; o professor promovendo "conversas sobre o seu dia-a-dia" e os alunos contribuindo com "exemplos do senso comum".

Este momento é classificado pelo investigador como $\boldsymbol{A}$-pelo diálogo ou exposição apresentam-se alguns factos ou aspetos relativos ao assunto. 
Segundo momento: o professor "trouxe vários exemplos" que "os alunos observam".

Este momento é classificado pelo investigador como $\boldsymbol{G}$ - o professor introduziu exemplos de situacõos da vida quotidiana relativas aos conceitos envolvidos.

Terceiro momento: o professor "realiza algumas experiências" que "os alunos observaram e questionaram".

Este momento é classificado pelo investigador como B- os alunos têm oportunidade de contactar com situações ou acontecimentos relativos ao assunto

Quarto momento: o professor propõe a "elaboração das fichas" a que os alunos "responderam com e sem ajuda".

Este momento é classificado pelo investigador como $\mathbf{E}$ - os conteúdos foram ensinados numa sequência ditada pela lógica das relaçôes entre si, dum modo muito próximo de como a matéria é estruturada no livro adotado.

Sequência pedagógica elaborada pelo investigador: $A>G>B>E$

Nesta sequência pedagógica o professor ensina o tema através do diálogo em que suscita a introdução de situações conhecidas dos alunos e introduz exemplos. Uma atividade de tipo prático com a função verificatória aparece no terceiro momento, a que segue a utilização das fichas didáticas do manual. Alguma dúvida sobre se os exemplos que diz apresentar não são apenas os objetos que a seguir experimentou para os alunos verem. De qualquer modo a leitura global seria a mesma.

\section{Sujeito $n^{\circ} 26$}

Primeiro momento: o professor promove a "apresentação oral do tema: os objetos na água", o "diálogo sobre o tema", a "colocação de questões", a "apresentação de imagens, fotografias, etc.", o "visionamento das imagens" e o "diálogo" a seu respeito.

Este momento é classificado pelo investigador como $\boldsymbol{A}$-pelo diálogo ou exposição apresentam-se alguns factos ou aspetos relativos ao assunto.

Segundo momento: O professor solicita a "colocação de questões"; a sua "escrita no quadro das questões colocadas... a partir das quais se vai desenrolar o tema" e a "cópia das questões".

Este momento é classificado pelo investigador como $\boldsymbol{D}$ - listaram-se um conjunto de questões ou interesses a partir dos quais se organizou a sequência das aprendizagens.

Terceiro momento: o professor faz a "entrega de livros e outros textos para consulta" e os alunos procuram respostas pela "leitura e recolha de informação".

Este momento é classificado pelo investigador como $\boldsymbol{E}$ - os conteúdos foram ensinados numa sequência ditada pela lógica das relações entre si, dum modo muito próximo de como a matéria é estruturada no livro adotado.

Quarto momento: o professor faz a "entrega de materiais para realizar a experiência" e "entrega de lista de registo das observações... do comportamento de cada material". Os alunos "realizam a experiência" e "elaboram uma lista com os materiais que flutuam e... que afundam...; "fazem o relatório da experiência [e] dão resposta às questões... Todos os materiais vão ao fundo? Todos os materiais flutuam?”.

Este momento é classificado pelo investigador como $\boldsymbol{B}$ - os alunos têm oportunidade de contactar com situações ou acontecimentos relativos ao assunto. 


\section{Sequência pedagógica elaborada pelo investigador: $A>D>E>B$}

Nesta sequência pedagógica o professor ensina o tema através do diálogo. É elaborada a partir do diálogo uma lista de questões a que os alunos procuram resposta pelo estudo do manual. Uma atividade de tipo prático com a função verificatória aparece no quarto momento. No padrão 1 estão incluídos sujeitos descrevendo uma metodologia mais fortemente transmissiva.

\section{Padrão 2 - perfil transmissivo baseado numa atividade prática (Anexo B)}

\section{Sujeito $\mathrm{n}^{\circ} 5$}

Primeiro momento: sob a questão "Porque é que os objetos flutuam?” posta pelo professor, "em grupo realização de uma experiência" e "preenchimento de grelha" pelos alunos. Este momento é classificado pelo investigador como $\boldsymbol{B}$ - os alunos têm oportunidade de contactar com situações ou acontecimentos relativos ao assunto.

Segundo momento: o professor promoveu a discussão sobre "as conclusões a que chegaram" pelo "diálogo em turma/registo das conclusões", "Solicitei... textos criativos sobre a razão de os barcos irem ao fundo, mas forneci... exemplo: era uma vez três navios e ficou apenas um e no final não ficou nenhum", o que leva os alunos a "leitura dos textos" e "diálogo sobre os textos".

Este momento é classificado pelo investigador como $\boldsymbol{A}$-pelo diálogo ou exposição apresentamse alguns factos ou aspetos relativos ao assunto. Embora os alunos procurem nos textos encontrar o fundamento para os seus textos/resposta, tudo se passa num ambiente de troca de pensamento envolvendo professor e alunos. De certo modo, este período é de reconstrução do pensamento dos alunos, embora não havendo de modo claro a explicitação conceptual e a realização de atividades promotoras do conflito cognitivo. No essencial, é comunicação do conhecimento através de um diálogo.

Terceiro e quarto momentos. Uma sequência de questões: "que materiais flutuam na água? Os alimentos flutuam? O gelo afunda-se?”, cada uma delas correspondendo a "em grupo realização de uma experiência", "preenchimento de grelha" e "diálogo em turma/registo das conclusões". Estes momentos sucessivos são classificados pelo investigador como B-os alunos têm oportunidade de contactar com situações ou acontecimentos relativos ao assunto e $\boldsymbol{A}$-pelo diálogo ou exposição apresentam-se alguns factos ou aspetos relativos ao assunto.

Estes serão os quatro momentos iniciais de uma sequência de ensino considerados na investigação. Uma sequência prolongada de atividades em que os alunos contactam com o conceito de modo prático a que se segue um diálogo que transmite o conceito.

Após estes momentos o professor dá a "sugestão de jogo pergunta/resposta" cuja “realização com atribuição de prémios" parte do "levantamento de dúvidas/perguntas dos alunos e pesquisa" que "os alunos, 3 a 3 pesquisam respostas para as suas perguntas" que "ilustram em Word e Power Point”. Este é um momento de orientação dos alunos para o estudo que é classificado pelo investigador como $\boldsymbol{E}$ - os conteúdos foram ensinados numa sequência ditada pela lógica das relações entre si, dum modo muito próximo de como a matéria é estruturada no livro adotado. Embora haja uma lista de perguntas que os alunos procuram responder, o investigador prefere considerar que não é mais que uma técnica de orientação do estudo do manual na lógica em que se pretende que o aluno aprenda o conceito. 
Sequência pedagógica elaborada pelo investigador: $B>A>B>A>\ldots>E$

Após um contacto prático com o fenómeno em estudo, os alunos aprendem o conceito pelo diálogo com o professor, repetindo-se este ciclo para vários aspetos do tópico.

\section{Sujeito $\mathbf{n}^{\mathbf{0}} 7$}

Primeiro momento: o professor "selecciona... objectos: plasticina, cortiça, clipes, pedaços de madeira, berlindes e alguidar com água" e "solicita... que os objectos sejam colocados um a um no alguidar". Os alunos "colocam o alguidar com água sobre a mesa" e "vão colocando os objetos previamente selecionados pelo professor, dentro do alguidar". Este momento é classificado pelo investigador como $\boldsymbol{B}$ - os alunos têm oportunidade de contactar com situações ou acontecimentos relativos ao assunto.

Segundo momento: o professor "questiona os alunos sobre o que está a acontecer" e estes "tecem opiniões sobre o que está a acontecer. Ex.: os objetos pesados vão ao fundo e os leves flutuam". A partir da vivência do fenómeno, o professor transmite pelo diálogo a sua mensagem (independentemente da sua correção científica). Este momento é classificado pelo investigador como $\boldsymbol{A}$-pelo diálogo ou exposição apresentam-se alguns factos ou aspetos relativos ao assunto.

Terceiro e quarto momentos - uma sequência de propostas de atividades: "propõe a construção de um barco de plasticina"; "e de seguida pede aos alunos que o coloquem na água”. Os alunos "constroem o barco de plasticina e colocam-no na água”. O professor "sugere posteriormente que cada objeto vá sendo colocado no barco" e os alunos "vão colocando cada um dos objetos dentro do barco". Em continuidade, o professor "questiona os alunos sobre o que está a acontecer, levando-os a tirar conclusões" e os alunos "tecem opiniões sobre o que está a acontecer". Ex. "o barco está muito carregado, mas não vai ao fundo, apesar do peso".

Estes momentos sucessivos são classificados pelo investigador como $\boldsymbol{B}$ - os alunos têm oportunidade de contactar com situações ou acontecimentos relativos ao assunto e $\boldsymbol{A}$-pelo diálogo ou exposição apresentam-se alguns factos ou aspetos relativos ao assunto.

Estes serão os quatro momentos iniciais de uma sequência de ensino considerados na investigação. Uma sequência prolongada de atividades em que os alunos contactam com o conceito de modo prático a que se segue um diálogo que transmite o conceito. Após estes momentos o professor "solicita... registo das conclusões... através de ficha entregue com o protocolo a seguir" e os alunos "registam as conclusões tiradas das observações e do diálogo com o professor", "o afundar, ou flutuar, dos objetos depende do espaço que eles ocupam dentro de água". Este é um momento de sistematização do conhecimento formal pretendido é classificado pelo investigador como $\boldsymbol{E}$ - os conteúdos foram ensinados numa sequência ditada pela lógica das relações entre si, dum modo muito próximo de como a matéria é estruturada no livro adotado.

Embora haja uma lista de perguntas que os alunos procuram responder, o investigador prefere considerar que não é mais que uma técnica de orientação do estudo do manual na lógica em que se pretende que o aluno aprenda o conceito.

\section{Sequência pedagógica elaborada pelo investigador: $B>A>B>A>\ldots>E$}

Após a introdução do fenómeno em estudo por meio de uma sequência de contactos práticos, os alunos aprendem o conceito pelo diálogo com o professor.

No padrão 2 verifica-se uma preocupação com a realização de atividades práticas como um primeiro passo a que se segue o modelo mais comum de transmissão do conceito através 
de um diálogo conduzido pelo professor. Neste padrão, no início da sequência pedagógica os alunos têm oportunidade para contactar com situações ou acontecimentos relativos ao assunto (1tem B), o que, no entanto não é mais que uma contextualização "experimental" do tópico, a partir do que se desenvolve um ensino transmissivo, ajustando-se a um programa que estipula que o conceito deve ser ensinado através de "experiências".

\section{Padrão 3 - perfil com traços construtivistas (Anexo C)}

\section{Sujeito $\mathrm{n}^{\circ} 8$}

Primeiro momento: colocada a "questão sobre o conceito de flutuação", os alunos dão as suas "respostas em diálogo coletivo" e face ao pedido de "relação entre o conceito e o quotidiano", dão "exemplos de flutuação no dia a dia... aproveitando as vivências...".

O professor "apresenta uma experiência e os materiais a usar" e "questiona os alunos sobre as expectativas". "Os alunos respondem" e o professor faz o "registo das hipóteses" e os alunos "conversam sobre as hipóteses". O professor orienta para a "formulação de um problema" e os alunos "formulam coletivamente a questão a solucionar". Este momento é classificado pelo investigador como $\boldsymbol{C}$ - os alunos expuseram pelo diálogo, on de outro modo, o que entendiam do tema ou assunto.

Segundo momento: o professor propõe "fazer a experiência onde diferentes objetos serão postos em água" e os alunos "fazem a experiência". "Registam-se no quadro os resultados da experiência" e os alunos "preenchem no quadro a grelha de interpretação da experiência". Este momento é classificado pelo investigador como B- os alunos têm oportunidade de contactar com situações ou acontecimentos relativos ao assunto.

Terceiro momento: com base na questão "diz-se que flutua e não flutua porquê?", o professor "leva os alunos a construir um conceito". "Os alunos chegam a conceitos e registam. Flutuação: massa, densidade, forma." O professor promove a "comparação das conclusões com as expectativas iniciais". Este momento é classificado pelo investigador como $\boldsymbol{A}$-pelo diálogo ou exposição apresentam-se alguns factos ou aspetos relativos ao assunto.

\section{Sequência pedagógica elaborada pelo investigador: $C>B>A>$}

Os alunos expressam o seu entendimento sobre o conceito e, face a uma situação, fazem previsões. Uma atividade prática permite verificar a correção do conceito e discutir em torno dos resultados a necessidade de reelaboração do conceito.

\section{Sujeito $\mathbf{n}^{\mathbf{0}} 27$}

Primeiro momento: o professor promove o "levantamento de ideias sobre flutuação/ afundamento" e pede aos alunos para "mencionarem exemplos de objetos que flutuem/afundem", obtendo dos alunos respostas como "flutuar: ficam em cima [superfície]/afundar: vão ao fundo" e "flutuam: p. ex., esferovite; não flutuam: p. ex., prego, berlinde”. O professor inquire os alunos sobre “porque será que alguns objetos se afundam e outros flutuam?”, pedindo para "agruparem objetos... de acordo com o que esperam que aconteça: flutuem ou afundem e fazerem o... registo". Os alunos justificam "porque uns são leves e outros são pesados" e "colocam objetos pesados no grupo dos... que afundam e leves no grupo dos... que flutuam". Este momento é classificado pelo investigador como $\boldsymbol{C}$ - os alunos expuseram pelo diálogo, ou de outro modo, o que entendiam do tema ou assunto. 
Segundo momento: o professor propõe uma "fase experimental" para "verificarem se as suas ideias estão corretas e assinalar as previsões incorretas". Este momento é classificado pelo investigador como $\boldsymbol{B}$ - os alunos têm oportunidade de contactar com situações ou acontecimentos relativos ao assunto.

Terceiro momento: a partir da "questão: o que será que faz com que existam objetos que flutuam e outros que não?" para a qual "não sabe que resposta dariam os alunos", o professor passaria a "explicar a partir das respostas a noção de impulsão, através de um esquema no quadro". Este momento é classificado pelo investigador como $\boldsymbol{A}$-pelo diálogo ou exposição apresentam-se alguns factos ou aspetos relativos ao assunto.

Este ciclo reinicia-se em torno de outros aspetos que entende contribuírem para a compreensão pelos alunos:

- $\quad$ Questão: será que todos os objetos estão sujeitos a essa força, mesmo aqueles que não flutuam? Experimentação: utilizarem o mesmo corpo, mas variar a sua forma. Discutir os resultados... de forma a perceberem que um objeto com o mesmo peso pode flutuar ou afundar, dependendo do seu volume/tamanho.

- $\quad$ Questão: será possível que um objeto que não flutue passe a flutuar? Colocar um objeto que afunde na água, fazer alterar a densidade de modo a que... passe a flutuar. Tirar conclusões.

Para cada um deles o ciclo repete-se: $\boldsymbol{C}$ - os alunos expuseram pelo diálogo, on de outro modo, o que entendiam do tema ou assunto; $\boldsymbol{B}$ - os alunos têm oportunidade de contactar com situações ou acontecimentos relativos ao assunto; $\boldsymbol{A}$ - pelo diálogo ou exposição apresentam-se alguns factos ou aspetos relativos ao assunto.

\section{Sequência pedagógica elaborada pelo investigador: $C>B>A>$}

Os alunos expressam o seu entendimento sobre o conceito e, face a uma situação, fazem previsões. Uma atividade prática permite verificar a correção do conceito e discutir em torno dos resultados a necessidade de reelaboração do conceito. O ciclo continua-se para vários aspetos, permitindo uma reconceptualização ampla do conceito.

Os sujeitos incluídos neste padrão mostram no início das suas sequências pedagógicas a presença nos dois primeiros componentes da sua sequência pedagógica, acontecimentos centrados nos alunos, ou neutro (B) (quadro 1).

\section{Discussão}

Em investigação anterior propôs-se uma metodologia com a qual se pretende identificar a perspetiva metodológica dos professores, identificando os que revelavam uma perspetiva tradicional, mais transmissiva e os que mostravam uma perspetiva mais construtivista. Nesse estudo os professores que autodefinem a sua prática corrente por uma sequência pedagógica de natureza construtivista, revelam também outras características da sua prática, coerentes com essa orientação metodológica.

A radiografia da prática proposta nesta investigação solicita ao professor que descreva de modo operacional a sequência de acontecimentos no início do ensino de um tópico programático muito concreto - flutuação -, relatando concretamente as ações efetuadas pelo professor e, em contraponto, os comportamentos dos alunos. Esta descrição, sendo escrita pelo próprio 
sobre a sua prática para ser apreciada pelo formador, será, mais que um instantâneo, um cenário construído, composto como uma síntese da sua melhor expressão prática, revelador das suas melhores conceptualizações. Os acontecimentos pedagógicos que os professores escrevem como descritores do que acontece na sua prática são interpretados pelo investigador e classificados em alguma das sete categorias de acontecimentos pedagógicos invariantes, originando uma sequência pedagógica para esse professor. Como em qualquer estudo interpretativo, a subjetividade do investigador é importante; todavia, ao descreverem comportamentos independentes como acontecimentos unitários, diminui a subjetividade de uma análise de conteúdos.

Os exemplos descritos mostram que há, mesmo descontando alguma diferença interpretativa, padrões de prática claros. Uma tendência para iniciar o processo de ensino por um diálogo, que contextualiza e apela às experiências anteriores dos alunos, e se articula com o processo de gradual transmissão da mensagem do professor, integrando nesse discurso os contributos dos alunos e as suas dificuldades. As atividades práticas a que o programa obriga vêm sempre depois, como verificação, feitas pelos alunos ou como demonstrações pelo professor. É também com este propósito que podem surgir outros exemplos em que se verifica o fenómeno.

Noutro padrão de prática, a contextualização inicial é baseada na realização da atividade experimental, executada pelos alunos ou pelo professor, após o que se segue a lógica de diálogo referida atrás. Em alguns casos, como nos exemplos descritos neste trabalho, este ciclo repete-se para diferentes aspetos do conceito.

Relativamente a estes dois padrões de prática, ressaltamos a reflexão de Morelatti et al. (2014) de que num ensino centrado no professor, mais que um ensino diretamente expositivo, se encontra a preocupação com a contextualização dos temas abordados na exploração de situações ligadas ao cotidiano, envolvendo os alunos numa participação mais efetiva, por meio de diálogos, debates ou análise de situações-problema. Frequentemente, este diálogo é visto pelos professores como uma oportunidade para os alunos expressarem as suas ideias a partir do qual se desenvolve o ensino.

Como um terceiro padrão descrevem-se casos em que um professor inicia a sua sequência apelando ao conhecimento dos alunos sobre o significado da palavra, a compreensão do conceito ou a previsão de acontecimentos, para depois propor atividades que verificam, ou põem em causa, as previsões e conceções dos alunos e acrescentam novos elementos. Apenas após, se discute o assunto e pelo diálogo se apresenta a versão curricular do conceito, numa lógica metodológica de traço construtivista. Este ciclo repete-se para diferentes aspetos do conceito.

A metodologia proposta neste estudo permite identificar padrões de prática e revela a potencialidade do seu uso no início de um curso de formação, permitindo a sua análise em muito pouco tempo, tornando possível iniciar um processo de formação contínua de professores pela explicitação do conhecimento metodológico dos professores e promover a sua discussão como eixo do processo formativo, deste modo cumprindo os objetivos a que se propunha. Como processo metodológico centrado na autodeclaração, os professores escrevem o que lhes apetece, no entanto, escrevem, eventualmente exagerando, na direção das melhores práticas que lhes estão ao alcance e segundo o seu melhor conhecimento das teorias pedagógicas. Um observador alheio, registando três aulas de um professor, não faz mais que uma síntese abusiva da teoria da prática de um professor, baseada em apenas três instantâneos, todavia, a metodologia proposta permite aceder à essência da representação da prática de um grupo de professores. 
Em posterior trabalho se descreverão os resultados quantitativos da aplicação da metodologia ao grupo estudado e sua comparação com outros parâmetros que diferenciam o grupo transmissivo do grupo de professores cuja sequência pedagógica apresenta característica de traço construtivista. De modo a fortalecer os contributos das metodologias experimentadas, importará em posterior investigação, cruzar a sua utilização com metodologias que procuram caracterizar as práticas por intermédio da identificação das crenças (PONTES PEDRAJAS; POYATO LÓPEZ; OLIVA MARTINEZ, 2016), conceções epistemológicas (RAVANAL MORENO; QUINTANILLA GATICA; LABARRERE SURDAY, 2012) e traços característicos do ensino (GIL FLORES, 2017).

\section{Referências}

CARMO, J. M. Desenvolvimento de um instrumento para a identificação de uma orientação construtivista no ensino de ciências. Revista Portuguesa de Educação, Braga, v. 29, n. 2, p. 163-184, 2016. DOI: https://doi.org/10.21814/rpe.6705.

GIL FLORES, J. Rasgos del profesorado asociados al uso de diferentes estrategias metodológicas en las clases de ciencias. Enseñanza de las Ciencias, Barcelona, v. 35, n. 1, p. 175-192, 2017. DOI: https://doi.org/10.5565/rev/ensciencias.1970.

MÉHEUT, M.; PSILLOS, D. Teaching-learning sequences: aims and tools for science education research. International Journal of Science Education, Abingdon, v. 26, n. 5, p. 515-535, 2004. DOI: https://doi.org/10.1080/09500690310001614762.

MORELATTI, M. R. M.; RABONI, P. C. A.; TEIXEIRA, L. R. M.; ORTEGA, E. M. V.; FÜRKOTTER, M.; RABONI, E. A. R. S.; RAMOS, R. C. Sequências didáticas descritas por professores de matemática e de ciências naturais da rede pública: possíveis padrões e implicações na formação pedagógica de professores. Ciência \& Educação, Bauru, v. 20, n. 3, p. 639-652, 2014. DOI: https://doi.org/10.1590/1516-73132014000300008.

PONTES PEDRAJAS, A; POYATO LÓPEZ, F. J.; OLIVA MARTINEZ, J. M.Creencias sobre el aprendizaje de las ciencias de los estudiantes del máster de profesorado de enseñanza secundaria. Didáctica de las Ciencias Experimentales y Sociales, Valencia, n. 31, p.137-163, 2016. DOI: https://doi.org/10.7203/dces.31.7881.

RAVANAL MORENO, E.; QUINTANILLA GATICA, M.; LABARRERE SURDAY, A. Concepciones epistemológicas del profesorado de biología en ejercicio sobre la enseñanza de la biología. Ciência \& Educação, Bauru, v. 18, n. 4, p. 875-895, 2012. DOI: https://doi. org/10.1590/S1516-73132012000400009.

RIVERO, A.; MARTÍN DEL POZO, R.; SOLÍS, E.; AZCÁRATE. P.; PORLÁN, R. Cambio del conocimiento sobre la enseñanza de las ciencias de futuros maestros. Enseñanza de las Ciencias, Barcelona, v. 35, n. 1, p. 29-52, 2017. DOI: https://doi.org/10.5565/rev/ ensciencias. 2068. 


\section{Anexo A - Padrão 1: padrão mais radicalmente transmissivo}

\begin{tabular}{|c|c|}
\hline Ações do professor & Ações do aluno \\
\hline $\mathrm{A}>\mathrm{G}>\mathrm{B}>\mathrm{E}$ & \\
\hline Questionando o conceito de flutuação & Respondendo dando exemplos e as suas opiniões \\
\hline Conversas sobre o seu dia a dia & Exemplos do senso comum \\
\hline Trouxe vários exemplos & Os alunos observam \\
\hline Realizei algumas experiências & Os alunos observaram e questionaram \\
\hline Elaboração das fichas & Responderam com e sem ajuda \\
\hline Caso \#26 A>D>E $>B$ & \\
\hline Apresentação oral do tema: os objetos na água & Diálogo sobre o tema; colocação de questões \\
\hline Apresentação de imagens, fotografias, etc. & $\begin{array}{l}\text { Visionamento das imagens; diálogo; colocação de } \\
\text { questões }\end{array}$ \\
\hline \multirow{2}{*}{$\begin{array}{l}\text { Escrita no quadro das questões colocadas... a } \\
\text { partir das quais se vai desenrolar o tema }\end{array}$} & Cópia das questões \\
\hline & Elaboração de grupos de trabalho \\
\hline Entrega de livros e outros textos para consulta & Leitura e recolha de informação \\
\hline Entrega de materiais para realizar a experiência. & Realizam a experiência \\
\hline $\begin{array}{l}\text { Entrega de lista de registo das observações... } \\
\text { do comportamento e cada material }\end{array}$ & $\begin{array}{l}\text { Elaboram uma lista com os materiais que flutuam } \\
\text { e... que afundam... }\end{array}$ \\
\hline $\begin{array}{l}\text { Entrega de lista de relatório da experiência } \\
\text { para registar as principais observações e tirar } \\
\text { conclusões }\end{array}$ & $\begin{array}{l}\text { Fazem o relatório da experiência (e) dão resposta } \\
\text { às questões...: todos os materiais vão ao fundo? } \\
\text { Todos os materiais flutuam }\end{array}$ \\
\hline $\begin{array}{l}\text { Em grande grupo solicita a apresentação dos } \\
\text { resultados de cada grupo }\end{array}$ & $\begin{array}{l}\text { Apresentação dos resultados e sua comparação } \\
\text { entre cada grupo. }\end{array}$ \\
\hline
\end{tabular}

Fonte: Elaborado pelo autor. 


\section{Anexo B - Padrão 2: padrão transmissivo baseado numa atividade prática}

\begin{tabular}{|c|c|}
\hline Ações do professor & Ações do aluno \\
\hline$\# 5 \quad \mathrm{~B}>\mathrm{A}>\mathrm{B}>\mathrm{A}$ & \\
\hline \multirow[t]{2}{*}{ Porque é que os objetos flutuam? } & Em grupo realização de uma experiência \\
\hline & Preenchimento de grelha \\
\hline Conclusões a que chegaram & Diálogo em turma/registo das conclusões \\
\hline $\begin{array}{l}\text { Solicitei... textos criativos sobre a razão de os } \\
\text { barcos irem ao fundo, mas forneci... exemplo: } \\
\text { "Era uma vez três navios e ficou apenas um e no } \\
\text { final não ficou nenhum" }\end{array}$ & $\begin{array}{l}\text { Leitura dos textos } \\
\text { Diálogo sobre os textos }\end{array}$ \\
\hline \multirow[t]{3}{*}{ Que materiais flutuam na água } & Em grupo realização de uma experiência \\
\hline & Preenchimento de grelha \\
\hline & Diálogo em turma/registo das conclusões \\
\hline \multirow[t]{3}{*}{ Os alimentos flutuam? } & Em grupo realização de uma experiência \\
\hline & Preenchimento de grelha \\
\hline & Diálogo em turma/registo das conclusões \\
\hline \multirow[t]{3}{*}{ O gelo afunda-se? } & Em grupo realização de uma experiência \\
\hline & Preenchimento de grelha \\
\hline & Diálogo em turma/registo das conclusões \\
\hline Sugestão de jogo pergunta/resposta & Realização com atribuição de prémios \\
\hline \multirow[t]{2}{*}{$\begin{array}{l}\text { Levantamento de dúvidas/perguntas dos alunos e } \\
\text { Pesquisa }\end{array}$} & 3 a 3 pesquisam respostas para as suas perguntas \\
\hline & Ilustrar em Word e Power Point \\
\hline Levantamento de questões sobre poluição da água & Trabalhos de grupo \\
\hline Propriedades da água & $\begin{array}{l}\text { Comunicação à turma: experiências, histórias e } \\
\text { pesquisas }\end{array}$ \\
\hline $\mathrm{B}>\mathrm{A}>\mathrm{B}>\mathrm{A}$ & \\
\hline $\begin{array}{l}\text { Seleciona... objetos: plasticina, cortiça, clipes, } \\
\text { pedaços de madeira, berlindes e alguidar com água. }\end{array}$ & Colocam o alguidar com água sobre a mesa. \\
\hline $\begin{array}{l}\text { Solicita... que os objetos sejam colocados um a um } \\
\text { no alguidar }\end{array}$ & $\begin{array}{l}\text { Vão colocando os objetos previamente } \\
\text { selecionados pelo professor, dentro do alguidar }\end{array}$ \\
\hline Questiona os alunos sobre o que está a acontecer. & $\begin{array}{l}\text { Tecem opiniões sobre o que está a acontecer. } \\
\text { Ex. “os objetos pesados vão ao fundo e os leves } \\
\text { flutuam”. }\end{array}$ \\
\hline Propõe a construção de um barco de plasticina & Constroem o barco de plasticina \\
\hline $\begin{array}{l}\text { E de seguida pede aos alunos que o coloquem na } \\
\text { água }\end{array}$ & E colocam-no na água \\
\hline $\begin{array}{l}\text { Sugere posteriormente que cada objeto vá sendo } \\
\text { colocado no barco }\end{array}$ & $\begin{array}{l}\text { Vão colocando cada um dos objetos dentro do } \\
\text { barco. }\end{array}$ \\
\hline $\begin{array}{l}\text { Questiona os alunos sobre o que está a acontecer, } \\
\text { levando-os a tirar conclusões }\end{array}$ & $\begin{array}{l}\text { Tecem opiniões sobre o que está a acontecer. Ex. } \\
\text { "o barco está muito carregado, mas não vai ao } \\
\text { fundo, apesar do peso". }\end{array}$ \\
\hline $\begin{array}{l}\text { Solicita... registo das conclusões... através de ficha } \\
\text { entregue com o protocolo a seguir. }\end{array}$ & $\begin{array}{l}\text { Registam as conclusões tiradas das observações } \\
\text { e do diálogo com o professor, E. "O afundar, ou } \\
\text { flutuar dos objetos depende do espaço que eles } \\
\text { ocupam dentro de água". }\end{array}$ \\
\hline
\end{tabular}

Fonte: Elaborado pelo autor. 


\section{Anexo C - Padrão 3: padrão com marcas construtivistas}

\begin{tabular}{|c|c|}
\hline Ações do professor & Ações do aluno \\
\hline Caso\#8 $\quad$ C $>$ B $>$ A & \\
\hline Questão Sobre o conceito de flutuação & Respostas em diálogo coletivo \\
\hline Relação entre o conceito e o quotidiano & $\begin{array}{l}\text { Exemplos de flutuação no dia a dia... } \\
\text { aproveitando as vivências... }\end{array}$ \\
\hline \multicolumn{2}{|l|}{$\begin{array}{l}\text { Apresentação de uma experiência: Apresentação dos } \\
\text { materiais a usar }\end{array}$} \\
\hline Questionar os alunos sobre as expectativas & Os alunos respondem \\
\hline Registo das hipóteses & Conversam sobre as hipóteses \\
\hline Formulação de um problema & $\begin{array}{l}\text {...formulam coletivamente a questão a } \\
\text { solucionar }\end{array}$ \\
\hline $\begin{array}{l}\text { Fazer a experiência onde diferentes objetos serão } \\
\text { postos em água... }\end{array}$ & Serão os alunos a fazer a experiência \\
\hline Registam-se no quadro os resultados da experiência & $\begin{array}{l}\text {...preenchem no quadro a grelha de } \\
\text { interpretação da experiência. }\end{array}$ \\
\hline \multicolumn{2}{|l|}{ Diz-se que flutua e não flutua porquê? } \\
\hline Leva-se os alunos a construir um conceito & $\begin{array}{l}\text { Os alunos chegam a conceitos e registam. } \\
\text { Flutuação: massa, densidade, forma. }\end{array}$ \\
\hline Compara-se as conclusões com as expectativas iniciais & \\
\hline
\end{tabular}

continua 


\section{Anexo C - Padrão 3: padrão com marcas construtivistas}

\begin{tabular}{|c|c|}
\hline Ações do professor & Ações do aluno \\
\hline $\mathrm{C}>\mathrm{B}>\mathrm{A}>$ & \\
\hline Levantamento de ideias sobre flutuação/afundamento & $\begin{array}{l}\text { Flutuar: ficam em cima (superfície)/Afundar: } \\
\text { vão ao fundo }\end{array}$ \\
\hline $\begin{array}{l}\text { Mencionarem exemplos de objetos que flutuem/ } \\
\text { afundem }\end{array}$ & $\begin{array}{l}\text { Flutuam: p. ex., esferovite; Não flutuam: } \\
\text { p.ex., prego, berlinde. }\end{array}$ \\
\hline $\begin{array}{l}\text { Porque será que alguns objetos se afundam e outros } \\
\text { flutuam? }\end{array}$ & Porque uns são leves e outros são pesados \\
\hline $\begin{array}{l}\text { Agruparem objetos... de acordo com o que esperam } \\
\text { que aconteça: flutuem ou afundem e fazerem o... } \\
\text { registo }\end{array}$ & $\begin{array}{l}\text { Colocarem objetos pesados no grupo dos... } \\
\text { que afundam e leves no grupo dos... que } \\
\text { flutuam }\end{array}$ \\
\hline \multicolumn{2}{|l|}{ Fase experimental: } \\
\hline \multicolumn{2}{|l|}{$\begin{array}{l}\text { Verificarem se as suas ideias estão corretas e assinalar } \\
\text { as previsões incorretas }\end{array}$} \\
\hline $\begin{array}{l}\text { Questão: O que será que faz com que existam objetos } \\
\text { que flutuam e outros que não? }\end{array}$ & Não sei que resposta dariam os alunos. \\
\hline \multicolumn{2}{|l|}{$\begin{array}{l}\text { Explicar a partir das respostas a noção de impulsão, } \\
\text { através de um esquema no quadro }\end{array}$} \\
\hline $\begin{array}{l}\text { Questão: Será que todos os objetos estão sujeitos a } \\
\text { essa força, mesmo aqueles que não flutuam? }\end{array}$ & $\begin{array}{l}\text { Provavelmente diriam que apenas há } \\
\text { impulsão sobre os corpos que flutuam. }\end{array}$ \\
\hline \multicolumn{2}{|l|}{$\begin{array}{l}\text { Experimentação: Utilizarem o mesmo corpo, mas } \\
\text { variar a sua forma }\end{array}$} \\
\hline \multicolumn{2}{|l|}{$\begin{array}{l}\text { Discutir os resultados... de forma a perceberem } \\
\text { que um objeto com o mesmo peso pode flutuar ou } \\
\text { afundar, dependendo do seu volume/tamanho. }\end{array}$} \\
\hline $\begin{array}{l}\text { Questão: será possível que um objeto que não flutue } \\
\text { passe a flutuar? }\end{array}$ & $\begin{array}{l}\text { Penso que os alunos diriam que não é } \\
\text { possível. }\end{array}$ \\
\hline \multicolumn{2}{|l|}{$\begin{array}{l}\text { Colocar um objeto que afunde, fazer alterar a } \\
\text { densidade de modo a que... passe a flutuar. }\end{array}$} \\
\hline Tirar conclusões & $\begin{array}{l}\text { Sempre que os alunos sintam dificuldade em } \\
\text { responder, podem recorrer a livros/manual } \\
\text { para encontrar uma resposta }\end{array}$ \\
\hline
\end{tabular}

Fonte: Elaborado pelo autor.

Artigo recebido em 08/05/2017. Aceito em 25/08/2018.

Contato: Universidade do Algarve, Escola Superior de Educação e Comunicação, R. Dr. Manuel Trindade, 4, $4^{\circ}$ Esq., Tavira 8800-417, Portugal. 
